\title{
Evaluation of Different Treatment Regimens for Relapsed and Refractory NHL: Single Institute Experience
}

\author{
Heba Sheha*, Mohamed Mekkawy, Hoda Hassan, Ola Nabih \\ Assuit University, Assiut, Egypt \\ Email: ^beboo0412@gmail.com
}

How to cite this paper: Sheha, H., Mekkawy, M., Hassan, H. and Nabih, O. (2019) Evaluation of Different Treatment Regimens for Relapsed and Refractory NHL: Single Institute Experience. Journal of Cancer Therapy, 10, 642-653.

https://doi.org/10.4236/jct.2019.108053

Received: July 10, 2019

Accepted: August 10, 2019

Published: August 13, 2019

Copyright $\odot 2019$ by author(s) and Scientific Research Publishing Inc. This work is licensed under the Creative Commons Attribution International License (CC BY 4.0).

http://creativecommons.org/licenses/by/4.0/

\begin{abstract}
Background and Aim: The treatment of choice for relapsed or refractory Non-Hodgkin Lymphoma (NHL) mainly, is High dose chemotherapy with autologous stem cell transplantation. However, its use is mostly restricted to patients responding to salvage chemotherapy. In this study, our aim was to evaluate outcome and toxicity of different treatment modalities of relapsed and refractory NHL. Patient and Methods: This retrospective study included 217 patients were diagnosed as refractory or relapsed NHL. Those patients received different treatment modalities as GDP (Gemcitabine, dexamethasone, cisplatin), DHAP (Dexamethasone, Cytarabine, and Cisplatin), MINE (Mitoxantrone, ifosfamide, etoposide and mesna), CHOP (Cyclophosphamide, Doxorubicin, Vincristine and Prednisone), and CVP (Cyclophosphamide, vincristine and prednisone). Results: The median age of patients in the study was 50 years. Patients who received DHAP showed ORR of $62 \%$, which was the highest response. The most common adverse effects were hematological which were more noticed in patients, received CHOP. Sixty one patients (54.5\%) had anemia, 54 patients (48.2\%) had neutropenia and 55 patients (49.1\%) had thrombocytopenia, but the difference between the different lines of treatment wasn't significant $p$ value of 0.95 . The median time to relapse is 10 months and the median survival time is 40 months. The 3-year PFS rates of all patients were $49.3 \%$, while the 3 year OS rates were $54.8 \%$. Conclusion: The overall and PFS didn't show any difference between different lines of treatment.
\end{abstract}

\section{Keywords}

Non Hodgkin Lymphoma, Progression Free Survival, Overall Response Rate

\section{Introduction}

Non-Hodgkin lymphomas (NHL) are a heterogeneous group of lymphoprolifer- 
ative disorders originating in B-lymphocytes, T-lymphocytes or natural killer (NK) cells. NK/T-cell lymphomas are very rare [1]. NHL includes many clinicopathologic subtypes, each with distinct epidemiologies; etiologies; morphologic, immunophenotypic, genetic, and clinical features; and responses to therapy. With respect to prognosis, NHLs can be divided into two groups, indolent and aggressive [2]. Indolent NHL types have a relatively good prognosis with a median survival as long as 20 years, but they usually are not curable in advanced clinical stages [3]. The aggressive NHLs grow faster and have shorter survival; the number of patients cured with intensive chemotherapy currently has been increasing [4]. A large number of new therapeutic protocols based on a combination of multi-drug chemotherapy, have been introduced for the treatment of patients with high-grade NHL [5]. Multi-drug chemotherapy produces an overall survival of 50\%-60\% at five years in aggressive NHL [6]. However, a significant proportion of patients relapsed, experiencing either failure after prolonged treatment, known as refractory disease, or relapsed after initial response, known as a relapsing disease [7]. The strategy for management of relapsed or refractory disease is to deliver salvage chemotherapy, followed by high dose chemotherapy and autologous stem-cell transplantation in responding patients [8]. There is no optimal salvage regimen for relapsed or refractory B-cell lymphoma; also there are no standard options of treatment for patient's response to second line regimens, nor for patients who are not eligible for transplant [9].

\section{Patients and Methods}

\subsection{Study Type and Duration}

The current retrospective study included 217 patients who were diagnosed as refractory or relapsed NHL (B or T) at Medical Oncology Department, Assiut University Hospitals from January 2011 to December 2015.

\subsection{Inclusion Criteria}

- Patient who are older than 18 years old;

- Histologically confirmed to have Non Hodgkin lymphoma;

- Clinically and radiologically confirmed to have relapsed and refractory;

- Stage from 1 to 4 Non Hodgkin lymphoma;

- Previously treated with CHOP, first line chemotherapy, non-metastatic;

- Furthermore, patient should have Eastern Cooperative Oncology Group performanous status (ECOG) $0-1$ with adequate hematologic, hepatic and renal functions including hemoglobin $>10 / \mathrm{dl}$, absolute neutrophil count $\geq$ $1500 / \mathrm{mm}^{3}$, platelets $\geq 100,000 / \mathrm{mm}^{3}$, serum bilirubin $<2 \mathrm{mg} / \mathrm{dl}$, both ALT and AST $\leq 2 \times$ upper limit of normal (ULN), alkaline phosphates $\leq 5 \times \mathrm{ULN}$, and serum creatinine $\leq 1.5 \mathrm{mg} / \mathrm{dl}$ or creatinine clearance $\geq 60 \mathrm{ml} / \mathrm{min}$.

\subsection{Exclusion Criteria}

- Prior history of cardiac disease (serious arrhythmia, heart failure, myocardial 
infarction, or unstable angina within the last 6 months);

- Active serious infection or a psychiatric illness.

\subsection{Study Design}

Patients were divided into 6 groups:

Group (1): 54 patients received Dexamethasone, Cytarabine, and Cisplatin (DHAP).

Group (2): 25 patients received Mitoxantrone, ifosfamide, etoposide and mesna (MINE).

Group (3): 13 patients received fludarabine, cyclophosphamide (FC).

Group (4): 8 patients received Cyclophosphamide, vincristine and prednisone (CVP)

Group (5): 5 patients received Gemcitabine, Cisplatin and Dexamethasone.

Group (6): 112 patients received Cyclophosphamide, Doxorubicin, Vincristine and Prednisone (CHOP).

All studied patients were subjected to the following: Full history taking, Complete physical examination, Laboratory investigations including $\mathrm{CBC}$, liver function test, kidney function test, $\mathrm{LDH}$, and bone marrow aspirate and biopsy., MSCT chest \& abdomen, Excisional lymph node biopsy, International Prognostic Index calculation, Evaluation of the patients (toxicity and response) done by:

a) Evaluate toxicity: signs of GIT toxicity as nausea, vomiting and diarrhea, signs of neurological toxicity as mood changes, restless, sleeping problems, unsteadiness, signs of hepatic toxicity as hyperbilirubinemia and raised liver enzymes (AST level $>38 \mathrm{U} / \mathrm{L}$, ALT level $>41 \mathrm{U} / \mathrm{L}$ ), and signs of anemia as complete blood count with differential count.

b) Evaluate response: by physical examination, MSCT chest and abdomen and Lugano response criteria for NHL [10] observed at the end of treatment of $6 \mathrm{cy}$ cles as complete response, partial response, stable disease, progressive disease.

\subsection{Statistical Analysis}

The results of study were tabulated and statistical analysis was carried out using statistical package spss version 23. using significant level $(p<0.05)$, chi square test was used to compare frequencies, M ANOVA, Survival curves were estimated with Kaplan Mayer method [11] and compared using Log-rank test.

\section{Results}

\subsection{Patient Characteristics $(n=217)$}

The median age of patients in the study was 50 years old with 116 (53.5\%) of patients were females. One hundred and twelve patients (51.6\%) were with ECOG performance status of 1133 patients (61.3\%) with B symptoms and the median LDH was 277. Most of the patients were B-NHL; 185 patients (85.3\%), 119 patients (54.8\%) were in stage 3 and 200 of patients (92.2\%) received CHOP as 1st line. One hundred and thirteen (52.1\%) of patients were refractory after receiving 1st line, 59 (56.7\%) of patients were relapsed before 1 year and $45(43.3 \%)$ 
after 1 year. Most of the patients 85 (39.2\%) were with low intermediate IPI, as shown in Table $1 \&$ Table 2.

Table 1. Base line patient's characteristics.

\begin{tabular}{|c|c|c|}
\hline & No. $(n=217)$ & $\%$ \\
\hline \multicolumn{3}{|l|}{ Age } \\
\hline Range & \multicolumn{2}{|c|}{$51-69$} \\
\hline Mean \pm SD & \multicolumn{2}{|c|}{$47.70 \pm 13.18$} \\
\hline Median (IQ) & \multicolumn{2}{|c|}{50.00} \\
\hline \multicolumn{3}{|l|}{ Sex } \\
\hline Male & 101 & 46.5 \\
\hline Female & 116 & 53.5 \\
\hline \multicolumn{3}{|l|}{ Performance status } \\
\hline 0 & 25 & 11.5 \\
\hline 1 & 112 & 51.6 \\
\hline 2 & 80 & 36.9 \\
\hline \multicolumn{3}{|l|}{ B symtom } \\
\hline Positive & 133 & 61.3 \\
\hline Negative & 84 & 38.7 \\
\hline \multicolumn{3}{|l|}{$\mathrm{LDH}$} \\
\hline Range & \multicolumn{2}{|c|}{$689-781$} \\
\hline Mean \pm SD & \multicolumn{2}{|c|}{$307.9954 \pm 150.3$} \\
\hline Median (IQ) & \multicolumn{2}{|c|}{277} \\
\hline \multicolumn{3}{|l|}{ Pathology } \\
\hline B cell-NHL & 185 & 85.3 \\
\hline T cell-NHL & 32 & 14.7 \\
\hline \multicolumn{3}{|l|}{ Stage } \\
\hline $1 \mathrm{~A}$ & 6 & 2.8 \\
\hline $1 \mathrm{~B}$ & 6 & 2.8 \\
\hline $2 \mathrm{~A}$ & 40 & 18.4 \\
\hline $2 \mathrm{~B}$ & 7 & 3.2 \\
\hline $3 \mathrm{~A}$ & 78 & 35.9 \\
\hline $3 \mathrm{~B}$ & 41 & 18.9 \\
\hline 4 & 39 & 18.0 \\
\hline \multicolumn{3}{|l|}{ 1st line } \\
\hline CHOP & 200 & 92.2 \\
\hline $\mathrm{R}-\mathrm{CHOP}$ & 17 & 7.8 \\
\hline \multicolumn{3}{|l|}{ Response } \\
\hline Refractory & 113 & 52.1 \\
\hline Relapse & 104 & 47.9 \\
\hline Before $1 \mathrm{Y}$ & 59 & 56.7 \\
\hline After $1 \mathrm{Y}$ & 45 & 43.3 \\
\hline \multicolumn{3}{|c|}{ International prognostic index } \\
\hline Low risk & 50 & 23 \\
\hline Low intermediate & 85 & 39.2 \\
\hline High intermediate & 46 & 21.2 \\
\hline High risk & 36 & 16.6 \\
\hline
\end{tabular}


Table 2. Patient's characteristic of different treatment groups.

\begin{tabular}{|c|c|c|c|c|c|c|c|}
\hline & $\begin{array}{l}\text { DHAP } \\
\mathrm{N}=54\end{array}$ & $\begin{array}{l}\text { MINE } \\
\mathrm{N}=25\end{array}$ & $\begin{array}{c}\text { Fludara + Endoxan } \\
\qquad \mathrm{N}=13\end{array}$ & $\begin{array}{l}\text { CVP } \\
\mathrm{N}=8\end{array}$ & $\begin{array}{l}\text { GDP } \\
\mathrm{N}=5\end{array}$ & $\begin{array}{c}\text { CHOP } \\
\mathrm{N}=112\end{array}$ & $P$ value \\
\hline Age & & & $44.62 .62 \pm 13.9$ & & & & \\
\hline Mean \pm SD & $52.53 \pm 8.3$ & $52.48 \pm 8.3$ & $44.63 \pm 13.9$ & $48 \pm 5.88$ & $32 \pm 2.24$ & $45.55 \pm 3.2$ & 0.000 \\
\hline \multicolumn{8}{|l|}{ Sex } \\
\hline Male & $32(59.3 \%)$ & $12(48 \%)$ & $5(38.5 \%)$ & $0(0 \%)$ & $0(0 \%)$ & $52(46.4 \%)$ & \multirow[t]{2}{*}{0.01} \\
\hline Female & $22(40.7 \%)$ & $13(52 \%)$ & $8(61.5 \%)$ & $8(100 \%)$ & $5(100 \%)$ & $60(53.6 \%)$ & \\
\hline \multicolumn{8}{|l|}{ PS } \\
\hline 0 & $5(9.3 \%)$ & $2(8 \%)$ & $3(23.1 \%)$ & $0(0 \%)$ & $4(80 \%)$ & $11(9.8 \%)$ & \multirow{3}{*}{0.000} \\
\hline 1 & $33(61.1 \%)$ & $16(63 \%)$ & $6(46.2 \%)$ & $3(37.5 \%)$ & $0(0 \%)$ & $54(48.2 \%)$ & \\
\hline 2 & $16(29.6 \%)$ & $7(28 \%)$ & $4(30.8 \%)$ & $5(62.5 \%)$ & $1(20 \%)$ & $47(42 \%)$ & \\
\hline \multicolumn{8}{|l|}{ Pathology } \\
\hline B cell NHL & $46(58.2 \%)$ & $18(72 \%)$ & $10(76.9 \%)$ & $7(87.5 \%)$ & $4(80 \%)$ & $100(89.3 \%)$ & \multirow[t]{2}{*}{0.32} \\
\hline T cell NHL & $8(14.8 \%)$ & $7(28 \%)$ & $3(23.1 \%)$ & $1(12.5 \%)$ & $1(20 \%)$ & $12(10.7 \%)$ & \\
\hline \multicolumn{8}{|l|}{$\mathrm{LDH}$} \\
\hline mean $\pm \mathrm{SD}$ & $295.32 \pm 123.20$ & $277.24 \pm 98.39$ & $319.92 \pm 55.86$ & $204 \pm 5.3$ & $384 \pm 8.9$ & $325.2 \pm 13.2$ & 0.162 \\
\hline \multicolumn{8}{|l|}{ B symptom } \\
\hline Positive & $33(61.1 \%)$ & $23(92 \%)$ & $7(53.8 \%)$ & $5(62.5 \%)$ & $5(100 \%)$ & $60(53.6 \%)$ & \multirow[t]{2}{*}{0.006} \\
\hline Negative & $21(38.9 \%)$ & $2(8 \%)$ & $6(46.2 \%)$ & $3(37.5 \%)$ & $0(0 \%)$ & $52(46.4 \%)$ & \\
\hline \multicolumn{8}{|l|}{ Stage } \\
\hline $1 \mathrm{~A}$ & $1(1.9 \%)$ & $0(0 \%)$ & $4(30.8 \%)$ & $0(0 \%)$ & $0(0 \%)$ & $1(0.9 \%)$ & \multirow{7}{*}{0.000} \\
\hline $1 \mathrm{~B}$ & $1(1.9 \%)$ & $4(16 \%)$ & $0(0 \%)$ & $0(0 \%)$ & $0(0 \%)$ & $1(0.9 \%)$ & \\
\hline $2 \mathrm{~A}$ & $12(22.2 \%)$ & $5(20 \%)$ & $0(0 \%)$ & $0(0 \%)$ & $0(0 \%)$ & $23(20.5 \%)$ & \\
\hline $2 \mathrm{~B}$ & $1(1.9 \%)$ & $0(0 \%)$ & $0(0 \%)$ & $0(0 \%)$ & $0(0 \%)$ & $6(5.4 \%)$ & \\
\hline $3 \mathrm{~A}$ & $23(42.6 \%)$ & $12(48 \%)$ & $1(7.7 \%)$ & $0(0 \%)$ & $1(20 \%)$ & $41(36.6 \%)$ & \\
\hline $3 \mathrm{~B}$ & $12(22.2 \%)$ & $0(0 \%)$ & $8(61.5 \%)$ & $4(50 \%)$ & $4(80 \%)$ & $13(11.6 \%)$ & \\
\hline 4 & $4(7.4 \%)$ & $4(16 \%)$ & $0(0 \%)$ & $4(50 \%)$ & $0(0 \%)$ & $27(24.1 \%)$ & \\
\hline \multicolumn{8}{|l|}{ 1st line } \\
\hline $\mathrm{CHOP}$ & $54(100 \%)$ & $25(100 \%)$ & $13(100 \%)$ & $8(100 \%)$ & $5(100 \%)$ & $95(84.8 \%)$ & \multirow[t]{2}{*}{0.016} \\
\hline R-CHOP & $0(0 \%)$ & $0(0 \%)$ & $0(0 \%)$ & $0(0 \%)$ & $0(0 \%)$ & $17(15.2 \%)$ & \\
\hline \multicolumn{8}{|l|}{ 1st Response } \\
\hline Refractory & $25(46.3 \%)$ & $8(32 \%)$ & $9(69.2 \%)$ & $0(0 \%)$ & $4(80 \%)$ & $67(59.8 \%)$ & \multirow{3}{*}{0.002} \\
\hline Relapsed & $29(53.7 \%)$ & $17(30.8 \%)$ & $4(30.8 \%)$ & $8(100 \%)$ & $1(20 \%)$ & $45(40.2 \%)$ & \\
\hline Before 1 y & $28(96.5 \%)$ & $6(35.3 \%)$ & $2(50 \%)$ & $5(62.5 \%)$ & $0(0 \%)$ & $18(40 \%)$ & \\
\hline After $1 \mathrm{y}$ & $1(3.4 \%)$ & $11(64.7 \%)$ & $2(50 \%)$ & $3(37.5 \%)$ & $1(100 \%)$ & $27(60 \%)$ & 0.89 \\
\hline \multicolumn{8}{|l|}{ IPI } \\
\hline Low risk & $7(13 \%)$ & $9(36 \%)$ & $3(23.1 \%)$ & $1(12.5 \%)$ & $4(80 \%)$ & $26(23.2 \%)$ & \multirow{4}{*}{0.05} \\
\hline Low intermediate & $24(44.4 \%)$ & $11(44 \%)$ & $4(30.8 \%)$ & $5(62.5 \%)$ & $1(20 \%)$ & $40(35.7 \%)$ & \\
\hline High intermediate & $9(16.7 \%)$ & $4(16 \%)$ & $4(30.8 \%)$ & $1(12.5 \%)$ & $0(0 \%)$ & $28(25 \%)$ & \\
\hline High risk & $14(25.9 \%)$ & $1(4 \%)$ & $2(15.4 \%)$ & $1(12.5 \%)$ & $0(0 \%)$ & $18(16.1 \%)$ & \\
\hline
\end{tabular}




\subsection{Treatment Outcome}

Response to 2 nd line was shown in Table 3.

Toxicity of different treatment lines was shown in Table 4.

Survival of patients was shown in Figures 1-4.

Table 3. Response to different 2 nd line regimens.

\begin{tabular}{|c|c|c|c|c|c|c|}
\hline & $\begin{array}{l}\text { DHAP } \\
\mathrm{N}=54\end{array}$ & $\begin{array}{l}\text { MINE } \\
\mathrm{N}=25\end{array}$ & $\begin{array}{c}\text { Fludara + Endoxan } \\
\qquad N=13\end{array}$ & $\begin{array}{l}\text { CVP } \\
\mathrm{N}=8\end{array}$ & $\begin{array}{l}\text { GDP } \\
\mathrm{N}=5\end{array}$ & $\begin{array}{c}\text { CHOP } \\
\mathrm{N}=112\end{array}$ \\
\hline CR & $14(25.9 \%)$ & $7(28.0 \%)$ & $3(23.1 \%)$ & $2(25.0 \%)$ & $2(40.0 \%)$ & $19(17.0 \%)$ \\
\hline PR & $20(37.0 \%)$ & $3(12.0 \%)$ & $2(15.4 \%)$ & $2(25.0 \%)$ & $1(20.0 \%)$ & $18(16.1 \%)$ \\
\hline Progression & $12(22.2 \%)$ & $8(32.0 \%)$ & $5(38.5 \%)$ & $2(25.0 \%)$ & $1(20.0 \%)$ & $38(33.9 \%)$ \\
\hline Stationary & $8(14.8 \%)$ & $7(28.0 \%)$ & $3(23.1 \%)$ & $2(25.0 \%)$ & $1(20.0 \%)$ & $37(33.0 \%)$ \\
\hline
\end{tabular}

Table 4. Toxicity of different 2 nd line regimens.

\begin{tabular}{|c|c|c|c|c|c|c|c|}
\hline & $\begin{array}{l}\text { DHAP } \\
\mathrm{N}=54\end{array}$ & $\begin{array}{l}\text { MINE } \\
\mathrm{N}=25\end{array}$ & $\begin{array}{c}\text { Fludara + Endoxan } \\
\qquad \mathrm{N}=13\end{array}$ & $\begin{array}{l}\text { CVP } \\
\mathrm{N}=8\end{array}$ & $\begin{array}{l}\text { GDP } \\
\mathrm{N}=5\end{array}$ & $\begin{array}{c}\text { CHOP } \\
\mathrm{N}=112\end{array}$ & $P$ value \\
\hline Anemia & $34(63 \%)$ & $12(48 \%)$ & $12(92.3 \%)$ & $4(50 \%)$ & $3(60 \%)$ & $61(54.5 \%)$ & 0.12 \\
\hline Neutropenia & $22(40.7 \%)$ & $11(44 \%)$ & $7(53.8 \%)$ & $1(12.5 \%)$ & $1(20 \%)$ & $54(48.2 \%)$ & 0.31 \\
\hline Thrombocytopenia & $27(50 \%)$ & $14(56 \%)$ & $7(53.8 \%)$ & $5(62.5 \%)$ & $2(40 \%)$ & $55(49.1 \%)$ & 0.95 \\
\hline Nausea & $32(59.3 \%)$ & $10(40 \%)$ & $7(53.8 \%)$ & $5(62.5 \%)$ & $3(60 \%)$ & $60(53.6 \%)$ & 0.71 \\
\hline $\mathrm{V}$ vomiting & $31(57.4 \%)$ & $14(56 \%)$ & $5(38.5 \%)$ & $4(50 \%)$ & $3(60 \%)$ & $62(55.4 \%)$ & 0.88 \\
\hline Diarrhea & $17(31.5 \%)$ & $12(48 \%)$ & $5(38.5 \%)$ & $2(25 \%)$ & $1(20 \%)$ & $40(35.7 \%)$ & 0.68 \\
\hline Neurotoxicity & $22(40.7 \%)$ & $12(48 \%)$ & $6(46.2 \%)$ & $4(50 \%)$ & $4(80 \%)$ & $39(34.8 \%)$ & 0.32 \\
\hline Hepatotoxicity & $21(38.9 \%)$ & $10(40 \%)$ & $2(15.4 \%)$ & $1(12.5 \%)$ & $0(0 \%)$ & $34(30.4 \%)$ & 0.18 \\
\hline Renal toxicity & $18(33.3 \%)$ & $7(28 \%)$ & $5(38.5 \%)$ & $3(37.5 \%)$ & $3(60 \%)$ & $40(41.1 \%)$ & 0.69 \\
\hline
\end{tabular}

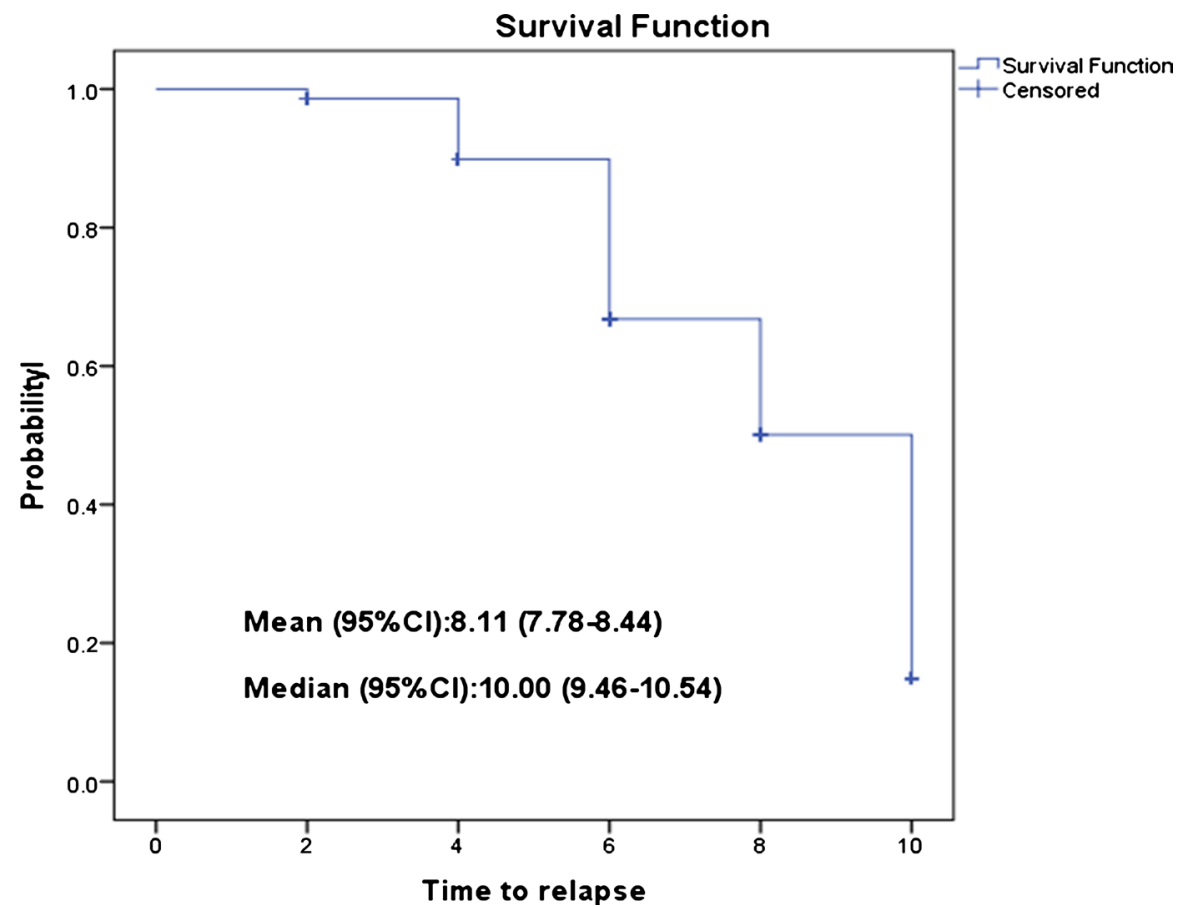

Figure 1. PFS of all patients; the median time to relapse was 10 months; $p$ value $=0.679$. 


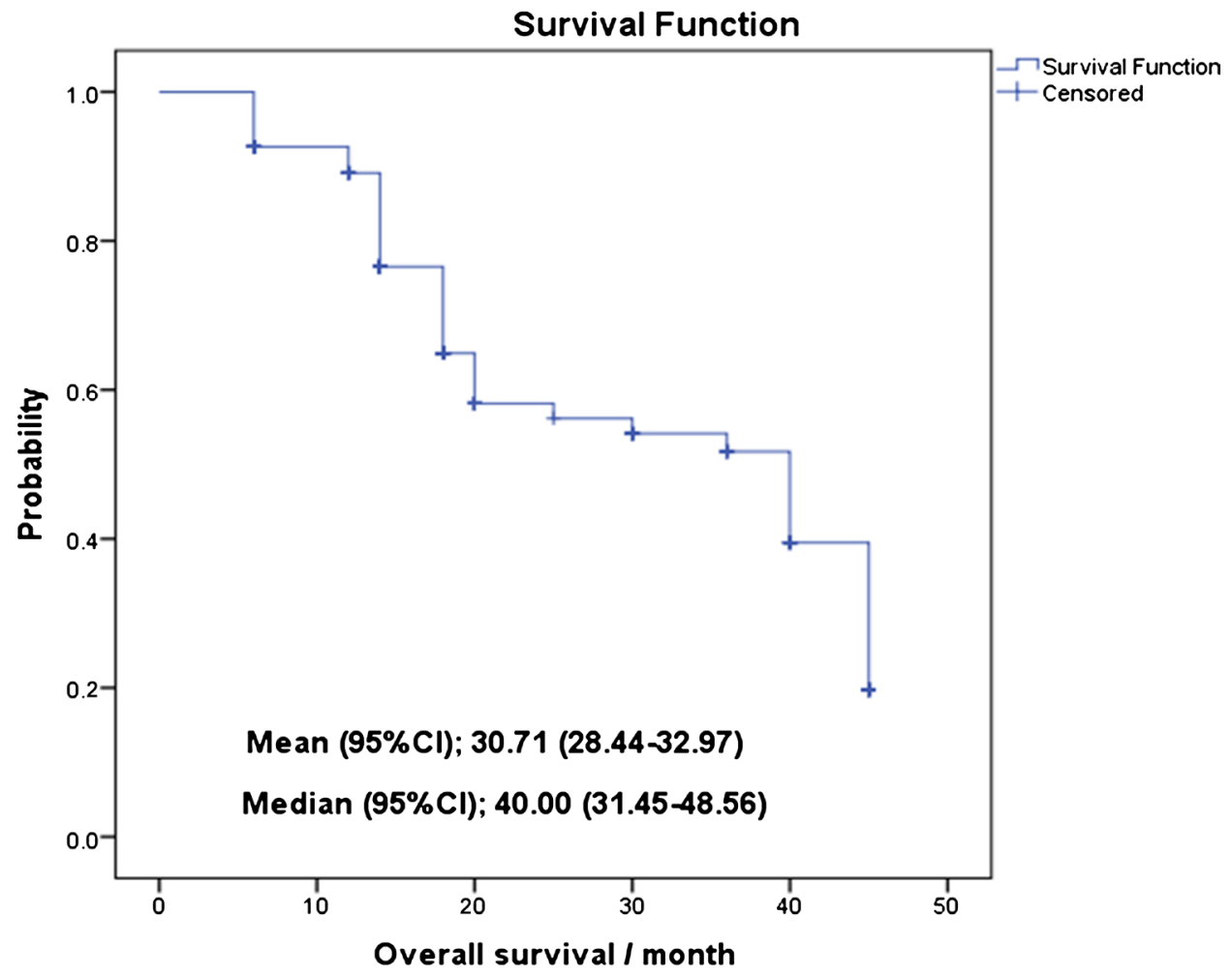

Figure 2. OS of all patients; the median survival time was 40 months; $p$ value $=0.917$.

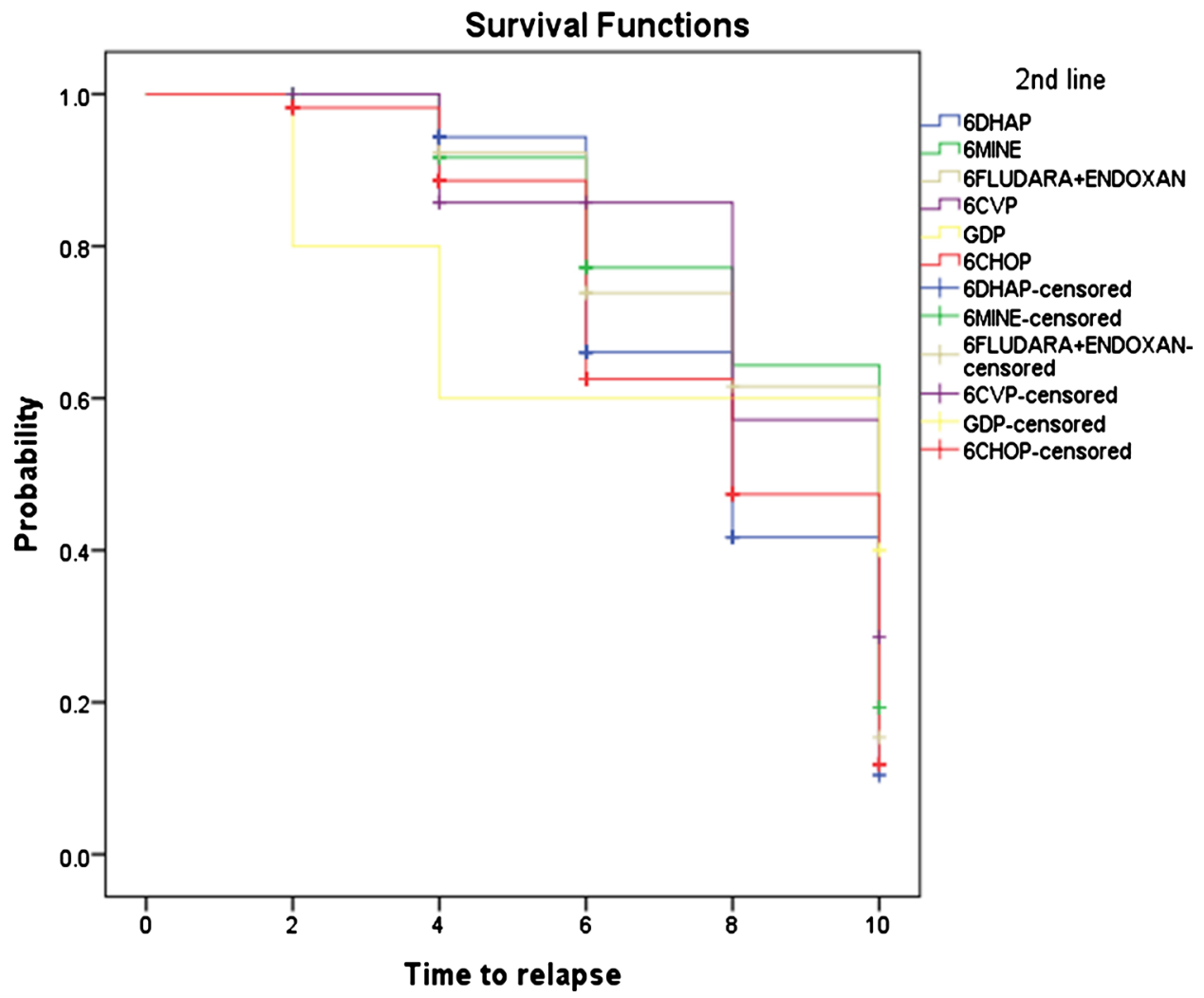

Figure 3. PFS of different treatment regimens; The median times to relapse were 8 months, 10 months, 10 months, 10 months and 8 months for patients who had received DHAP, MINE, Fludarabine \& Cyclophosphamide, CVP, GDP and CHOP with no significant difference; $p$ value $=0.679$. 


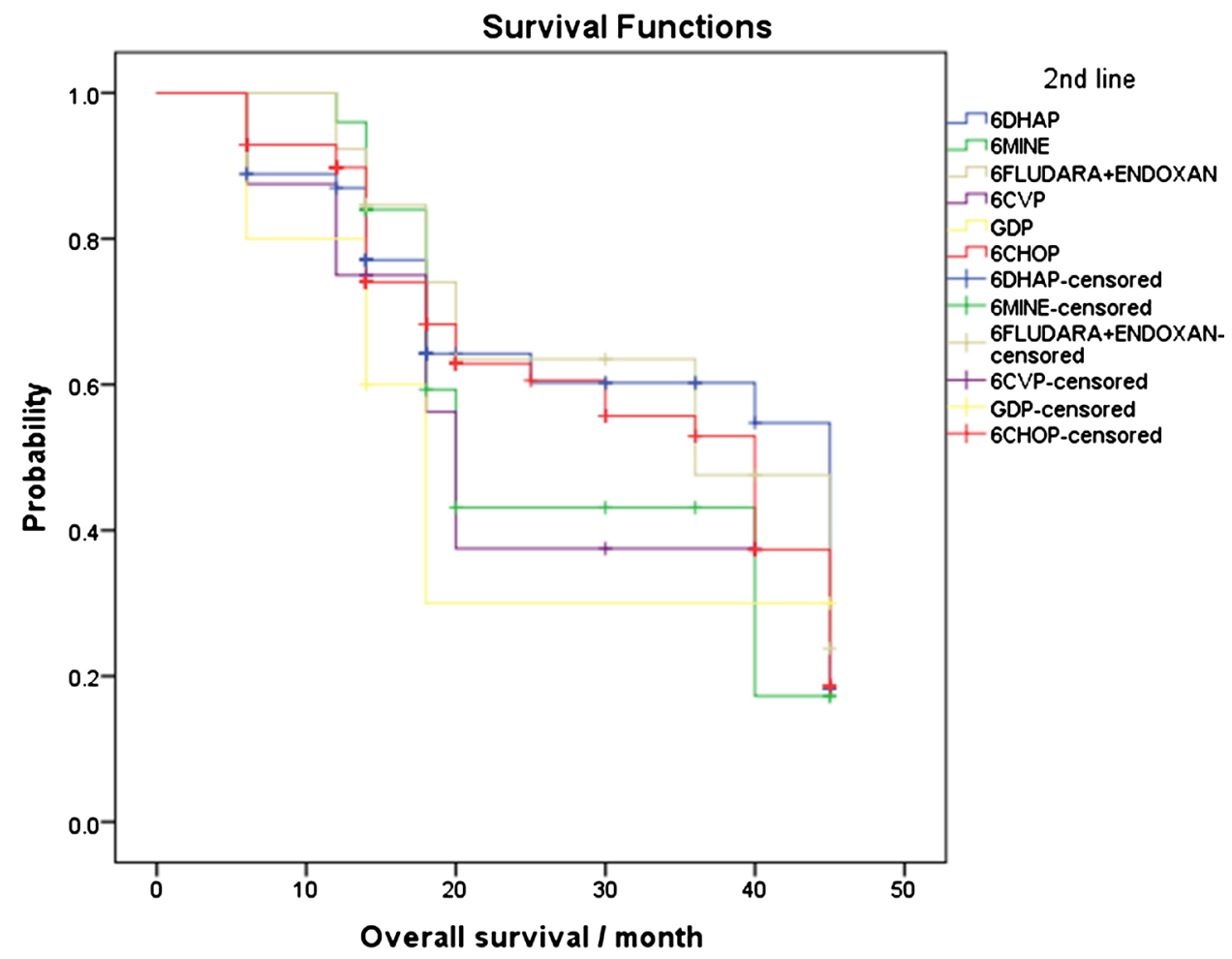

Figure 4. OS of different treatment regimens; The Median survival times were 45 months, 20 months, 36 months, 20 months, 18 months and 40 months for patients who received DHAP, MINE, Fludarabine and Cyclophosphamide, CVP, GDP and CHOP, with no significant difference; $p$ value $=0.917$.

\section{Discussion}

Several attempts have been made to prolong survival of patients with relapsed and refractory NHL [12]. Refractory or progressive disease is identified during the post-treatment response evaluation. The treatment of patients with relapsed or refractory lymphomas remains challenging. In general, the standard care is high-dose chemotherapy followed by autologous stem cell transplant (ASCT) for patients who are sensitive to salvage chemotherapy. There are no standard options of treatment for patients who show no response to second-line regimens, nor for patients who are not eligible for transplants [13]. In developing countries with limited resources as Egypt, high dose chemotherapy followed by ASCT is not always an option of treatment in relapsed and refractory lymphomas due to a small number of transplant centers across the country, long waiting lists and limited resources [14].

Regarding the response rate, the ORR in this study was higher in patients receiving DHAP and GDP but there was no statistical difference between the different lines of treatment. These findings were in agreement with that of Ismaeil., et al. who reported that the ORR was $65 \%$ and $67.6 \%$ in patients who had received GDP and DHAP respectively [15]. Conversely, this finding was higher than that of Abali, et al. who reported ORR of $48 \%$ in the DHAP group [16].

As regard treatment toxicity, the most common adverse effect was hemato- 
logical toxicity which was more noticed with patients received CHOP but the difference between the different lines of treatment wasn't significant. Neutropenia and anemia in patients who had received CHOP were slightly higher than that of KLAUS, et al. who reported a rate of $42 \%$ and $44 \%$ in their patients respectively [17].

Furthermore, there was no significant difference between different regimens in the occurrence of thrombocytopenia. Crump, et al. reported that thrombocytopenia occurred in $31 \%$ and $47 \%$ of patients who had received GDP and DHAP respectively [18].

As regard the non-hematological toxicities, nausea, vomiting, and diarrhea were the most common adverse effect which were more in patients who had received DHAP, but the difference wasn't significant. This finding was in agreement with that of Ismaeil, et al. who reported that nausea and vomiting were the most common non-hematologic toxicities in the majority of patients who received GDP and DHAP with a non-significant difference [15].

As regard the survival analysis performed in this study, the 3-year survival rate of patients received MINE was higher than that of Haung, et al. who reported the 1- and 2-year survival rates of $34.2 \%$ and $7.9 \%$, respectively [19].

The survival rates were moderate in patients who had received DHAP. This finding was higher than that of $\mathrm{Li}$, et al. who reported a median survival time of 8.3 months, and 1-year and 2-year survival rates of $30.8 \%$ and $19.3 \%$, respectively [20].

The 3-year survival rate of patients received GDP was higher than that of Fan, et al. who reported 1-year overall survival rate of $41.7 \%$ [21].

Wang, et al. reported the 1- and 2-year PFS rates of $54.5 \%$ and $45.4 \%$ and the 1 and 2-year OS rates of $72.7 \%$ and $54.7 \%$ for patients who had received GDP [22].

As regard CVP regimen, the 3 year PFS was low. Hochster, et al. reported PFS estimates at 2 and 4 years of $42 \%$ and 34\%, which was higher than that of our results. The difference may be attributed to the addition of Rituximab to their CVP regimen [23].

\section{Conclusion}

From the results of the current study, we conclude that relapsed and refractory disease continued to represent the most significant challenge in treating NHL with no difference between different lines of treatment. The hematological toxicity, GIT toxicity, hepatoxocitiy, neurotoxicity and renal toxicity didn't show a significant difference between investigated lines of treatment. The overall and PFS didn't show any difference between different lines of treatment while the low response and survival rates mandate the need to add rituximab to 2 nd line treatment and to proceed to bone marrow transplantation in eligible patients.

\section{Conflicts of Interest}

The authors declare no conflicts of interest regarding the publication of this paper. 


\section{References}

[1] Siegel, R.L., Miller, K.D. and Jemal, A. (2015) Cancer Statistics, 2015. CA: A Cancer Journal for Clinicians, 65, 5-29. https://doi.org/10.3322/caac.21254

[2] Shustik, J., Quinn, M., Connors, J.M., Gascoyne, R.D., Skinnider, B. and Sehn, L.H. (2011) Follicular Non-Hodgkin Lymphoma Grades 3A and 3B Have a Similar Outcome and Appear Incurable with Anthracycline-Based Therapy. Annals of Oncology: Official Journal of the European Society for Medical Oncology, 22, 1164-1169. https://doi.org/10.1093/annonc/mdq574

[3] Tan, D., Horning, S.J., Hoppe, R.T., Levy, R., Rosenberg, S.A., Sigal, B.M., et al. (2013) Improvements in Observed and Relative Survival in Follicular Grade 1-2 Lymphoma during 4 Decades: The Stanford University Experience. Blood, 122, 981-987. https://doi.org/10.1182/blood-2013-03-491514

[4] Zhang, Q.Y. and Foucar, K. (2009) Bone Marrow Involvement by Hodgkin and Non-Hodgkin Lymphomas. Hematology/Oncology Clinics of North America, 23, 873-902. https://doi.org/10.1016/j.hoc.2009.04.014

[5] Witzig, T.E., Nowakowski, G.S., Habermann, T.M., Goy, A., Hernandez-Ilizaliturri, F.J., Chiappella, A., et al. (2015) A Comprehensive Review of Lenalidomide Therapy for B-Cell Non-Hodgkin Lymphoma. Annals of Oncology: Official Journal of the European Society for Medical Oncology, 26, 1667-1677.

https://doi.org/10.1093/annonc/mdv102

[6] Seshadri, T., Kuruvilla, J., Crump, M. and Keating, A. (2008) Salvage Therapy for Relapsed/Refractory Diffuse Large B Cell Lymphoma. Biology of Blood and Marrow Transplantation: Journal of the American Society for Blood and Marrow Transplantation, 14, 259-267. https://doi.org/10.1016/j.bbmt.2007.11.013

[7] Moccia, A.A., Hitz, F., Hoskins, P., Klasa, R., Power, M.M., Savage, K.J., et al. (2017) Gemcitabine, Dexamethasone, and Cisplatin (GDP) Is an Effective and Well-Tolerated Salvage Therapy for Relapsed/Refractory Diffuse Large B-Cell Lymphoma and Hodgkin Lymphoma. Leukemia \& Lymphoma, 58, 324-332.

https://doi.org/10.1080/10428194.2016.1193852

[8] Magnano, L., Balague, O., Dlouhy, I., Rovira, J., Karube, K., Pinyol, M., et al. (2017) Clinicobiological Features and Prognostic Impact of Diffuse Large B-Cell Lymphoma Component in the Outcome of Patients with Previously Untreated Follicular Lymphoma. Annals of Oncology: Official Journal of the European Society for Medical Oncology, 28, 2799-2805. https://doi.org/10.1093/annonc/mdx407

[9] Park, B.B., Kim, W.S., Suh, C., Shin, D.Y., Kim, J.A., Kim, H.G., et al. (2015) Salvage Chemotherapy of Gemcitabine, Dexamethasone, and Cisplatin GDP for Patients with Relapsed or Refractory Peripheral T-Cell Lymphomas: A Consortium for Improving Survival of Lymphoma (CISL) Trial. Annals of Hematology, 94, 1845-1851. https://doi.org/10.1007/s00277-015-2468-y

[10] Lister, T.A., Crowther, D., Sutcliffe, S.B., Glatstein, E., Canellos, G.P., Young, R.C., et al. (1989) Report of a Committee Convened to Discuss the Evaluation and Staging of Patients with Hodgkin's Disease: Cotswolds Meeting. Journal of Clinical Oncology: Official Journal of the American Society of Clinical Oncology, 7, 1630-1636. https://doi.org/10.1200/JCO.1989.7.11.1630

[11] Kaplan, E.L. and Meier, P. (1958) Nonparametric Estimation from Incomplete Observations. Journal of the American Statistical Association, 53, 457-481. https://doi.org/10.1080/01621459.1958.10501452

[12] Gangatharan, S. and Kuruvilla, J. (2013) Relapsed and Refractory Aggressive NHL: Time for a Change. Transfusion and Apheresis Science, 49, 72-79. 
https://doi.org/10.1016/j.transci.2013.05.029

[13] Rybka, J., Jurczak, W., Giza, A., Paszkiewicz-Kozik, E., Kumiega, B., Drozd-Sokolowska, J., et al. (2015) Gemcitabine-Based Treatment in Poor-Prognosis Patients with Relapsed and Refractory Hodgkin Lymphoma and Non-Hodgkin Lymphoma Multicenter Polish Experience. Advances in Clinical and Experimental Medicine: Official Organ Wroclaw Medical University, 24, 783-789. https://doi.org/10.17219/acem/34795

[14] RaniaHafez, S. and Ismail, M. (2018) Definitive Salvage Chemotherapy for the Treatment of Refractory/Relapsed Non-Hodgkin Lymphoma, a Single Center Experience. Alexandria Journal of Medicine, 54, 679-683. https://doi.org/10.1016/j.ajme.2018.07.006

[15] Ismail, S.A., Han, R., Sanborn, S.L., Stevens, S.R., Cooper, K.D., Wood, G.S., et al. (2007) Immunohistochemical Staining for CD45R Isoforms in Paraffin Sections to Diagnose Mycosis Fungoides-Type Cutaneous T-Cell Lymphoma. Journal of the American Academy of Dermatology, 56, 635-642.

https://doi.org/10.1016/j.jaad.2006.08.069

[16] Abali, H., Urun, Y., Oksuzoglu, B., Budakoglu, B., Yildirim, N., Guler, T., et al. (2008) Comparison of ICE (Ifosfamide-Carboplatin-Etoposide) versus DHAP (Cytosine Arabinoside-Cisplatin-Dexamethasone) as Salvage Chemotherapy in Patients with Relapsed or Refractory Lymphoma. Cancer Investigation, 26, 401-406. https://doi.org/10.1080/07357900701788098

[17] Sweetenham, J., Hieke, K., Kerrigan, M., Howard, P., Smartt, P.F., McIntyre, A.M., et al. (1999) Cost-Minimization Analysis of CHOP, Fludarabine and Rituximab for the Treatment of Relapsed Indolent B-Cell Non-Hodgkin's Lymphoma in the UK. British Journal of Haematology, 106, 47-54. https://doi.org/10.1046/j.1365-2141.1999.01515.x

[18] Crump, M., Kuruvilla, J., Couban, S., MacDonald, D.A., Kukreti, V., Kouroukis, C.T., et al. (2014) Randomized Comparison of Gemcitabine, Dexamethasone, and Cisplatin versus Dexamethasone, Cytarabine, and Cisplatin Chemotherapy before Autologous Stem-Cell Transplantation for Relapsed and Refractory Aggressive Lymphomas: NCIC-CTG LY.12. Journal of Clinical Oncology: Official Journal of the American Society of Clinical Oncology, 32, 3490-3496.

https://doi.org/10.1200/JCO.2013.53.9593

[19] Park, B.B., Kim, W.S., Eom, H.S., Kim, J.S., Lee, Y.Y., Oh, S.J., et al. (2011) Salvage Therapy with Gemcitabine, Ifosfamide, Dexamethasone, and Oxaliplatin (GIDOX) for B-Cell Non-Hodgkin's Lymphoma: A Consortium for Improving Survival of Lymphoma (CISL) Trial. Investigational New Drugs, 29, 154-160. https://doi.org/10.1007/s10637-009-9320-y

[20] Li, Y.H., Jiang, W.Q., Huang, H.Q., Zhang, L., Liu, D.G., Xu, R.H., et al. (2002) Preliminary Study on DHAP Regimen for Patients with Relapsed and Refractory Non-Hodgkin's Lymphoma. Chinese Journal of Cancer, 21, 900-902.

[21] Fan, Y., Huang, Z.Y., Luo, L.H. and Yu, H.F. (2008) Efficacy of GDP Regimen (Gemcitabine, Dexamethasone, and Cisplatin) on Relapsed or Refractory Aggressive Non-Hodgkin's Lymphoma: A Report of 24 Cases. Chinese Journal of Cancer, 27, 1222-1225.

[22] Wang, J.J., Dong, M., He, X.-H., Li, Y.-X. and Wang, W.-H. (2016) GDP (Gemcitabine, Dexamethasone, and Cisplatin) Is Highly Effective and Well-Tolerated for Newly Diagnosed Stage IV and Relapsed/Refractory Extranodal Natural Killer/T-Cell Lymphoma, Nasal Type. 
[23] Hochster, H., Weller, E., Gascoyne, R.D., Habermann, T.M., Gordon, L.I., Ryan, T., et al. (2009) Maintenance Rituximab after Cyclophosphamide, Vincristine, and Prednisone Prolongs Progression-Free Survival in Advanced Indolent Lymphoma: Results of the Randomized Phase III ECOG1496 Study. Journal of Clinical Oncology: Official Journal of the American Society of Clinical Oncology, 27, 1607-1614. https://doi.org/10.1200/JCO.2008.17.1561 